\title{
Ammonium cyanate: a DFT study of crystal structure, rotational barriers and vibrational spectrum
}

\author{
ALI ALAVI ${ }^{1 *}$, R. JULIAN C. BROWN ${ }^{2}$, SCOTT HABERSHON ${ }^{3}$, \\ KENNETH D. M. HARRIS ${ }^{3 *}$ and ROY L. JOHNSTON ${ }^{3 *}$ \\ ${ }^{1}$ Chemistry Department, University of Cambridge, Cambridge CB2 1EW, UK \\ ${ }^{2}$ Chemistry Department, Queen's University, Kingston ON, K7L 3N6, Canada \\ ${ }^{3}$ School of Chemistry, University of Birmingham, Edgbaston, Birmingham B15 2TT, UK
}

(Received 15 January 2004; revised version accepted 9 March 2004)

\begin{abstract}
The crystal structure, rotational barriers and vibrational spectrum of ammonium cyanate have been studied by DFT calculations. The results show that, in the most stable structure, the ammonium ion is oriented such that each $\mathrm{N}-\mathrm{H}$ bond points towards the $\mathrm{N}$ atoms of a cyanate anion giving rise to $\mathrm{N}-\mathrm{H} \cdots \mathrm{N}$ hydrogen bonding, rather than $\mathrm{N}-\mathrm{H} \cdots \mathrm{O}$ hydrogen bonding. The $\mathrm{N}-\mathrm{C}$ and $\mathrm{C}-\mathrm{O}$ bond lengths suggest that the structure of the anion in the crystal is best described as ${ }^{-} \mathrm{N}=\mathrm{C}=\mathrm{O}$. These structural features are in agreement with recent results from neutron diffraction. At the transition state for rotation of the ammonium cation about an $\mathrm{N}-\mathrm{H}$ bond, the cation is displaced and distorted from its equilibrium configuration. The barrier to the rotation of the ammonium cation about the $\overline{4}$ axis is found to be larger than the minimum barrier to rotation about an $\mathrm{N}-\mathrm{H}$ bond, suggesting that the latter is the preferred rotational mode.
\end{abstract}

\section{Introduction}

Ammonium cyanate $\mathrm{NH}_{4} \mathrm{NCO}$ has long held an interesting position in chemistry. Historically, a link between the organic and inorganic branches of the subject was established by the reaction discovered by Wöhler in 1828 , in which ammonium cyanate is converted to urea, $\left(\mathrm{NH}_{2}\right)_{2} \mathrm{CO}[1,2]$. However, the structure of crystalline ammonium cyanate was not determined until recently $[3,4]$.

Two valence bond structures, with opposite polarity, can be drawn for the isolated cyanate ion:

\section{Structure I: $\quad{ }^{-} \mathrm{N}=\mathrm{C}=\mathrm{O}$ \\ Structure II: $\quad \mathrm{N} \equiv \mathrm{C}-\mathrm{O}^{-}$.}

Bond lengths in the gas phase cyanate ion determined from photoelectron spectra [5] are $r(\mathrm{~N}-\mathrm{C})=1.17(1) \AA$ and $r(\mathrm{C}-\mathrm{O})=1.26(1) \AA$, which suggests that Structure II is the better description for the anion in the gas phase. There have been several ab initio studies of the isolated anion, which yield a range of optimized bond lengths but agree with experiment in predicting that the $\mathrm{N}-\mathrm{C}$ bond is shorter than the $\mathrm{C}-\mathrm{O}$ bond [68]. However, details of the geometry of the cyanate

*Authors for correspondence. e-mail: asa10@cam.ac.uk; k.d.m.harris@bham.ac.uk; r.l.johnston@bham.ac.uk anion could be influenced by hydrogen bonding, as in the crystal structure of ammonium cyanate.

Recently, the structural properties of crystalline ammonium cyanate have been studied by both X-ray [3] and neutron [4] powder diffraction experiments. The structure is tetragonal, with two formula units per unit cell, and the space group is $P 4 / n m m$ [4]. The linear anions lie on the four-fold axes parallel to the $c$ axis and the cations are located at sites of -4 symmetry, with the hydrogen atoms lying on mirror planes. Around each ammonium ion there are four oxygen and four nitrogen atoms from eight different cyanate anions (figure 1). These atoms are arranged in a nearly cubic fashion. For each ammonium ion, there are two distinguishable orientations (figure 2), in which all $\mathrm{N}-\mathrm{H}$ bonds point either to the $\mathrm{N}$ atoms of the cyanate anions (forming four $\mathrm{N}-\mathrm{H} \cdots \mathrm{N}$ hydrogen bonds) or to the $\mathrm{O}$ atoms of the cyanate anions (forming four $\mathrm{N}-\mathrm{H} \ldots \mathrm{O}$ hydrogen bonds). These two orientations are non-equivalent. The analysis of neutron diffraction data for the deuterated salt showed that the ammonium ion is oriented with the $\mathrm{N}-\mathrm{H}$ bonds pointing towards the $\mathrm{N}$ atoms of the anions, rather than the $\mathrm{O}$ atoms [4]. The bond lengths determined from neutron diffraction at $14 \mathrm{~K}$ are $r(\mathrm{~N}-\mathrm{C})=1.191(3) \AA \quad$ and $\quad r(\mathrm{C}-\mathrm{O})=1.215(6) \AA$. These bond lengths suggest that, in terms of the valence bond model, the electronic structure of the anion shifts 
(a)
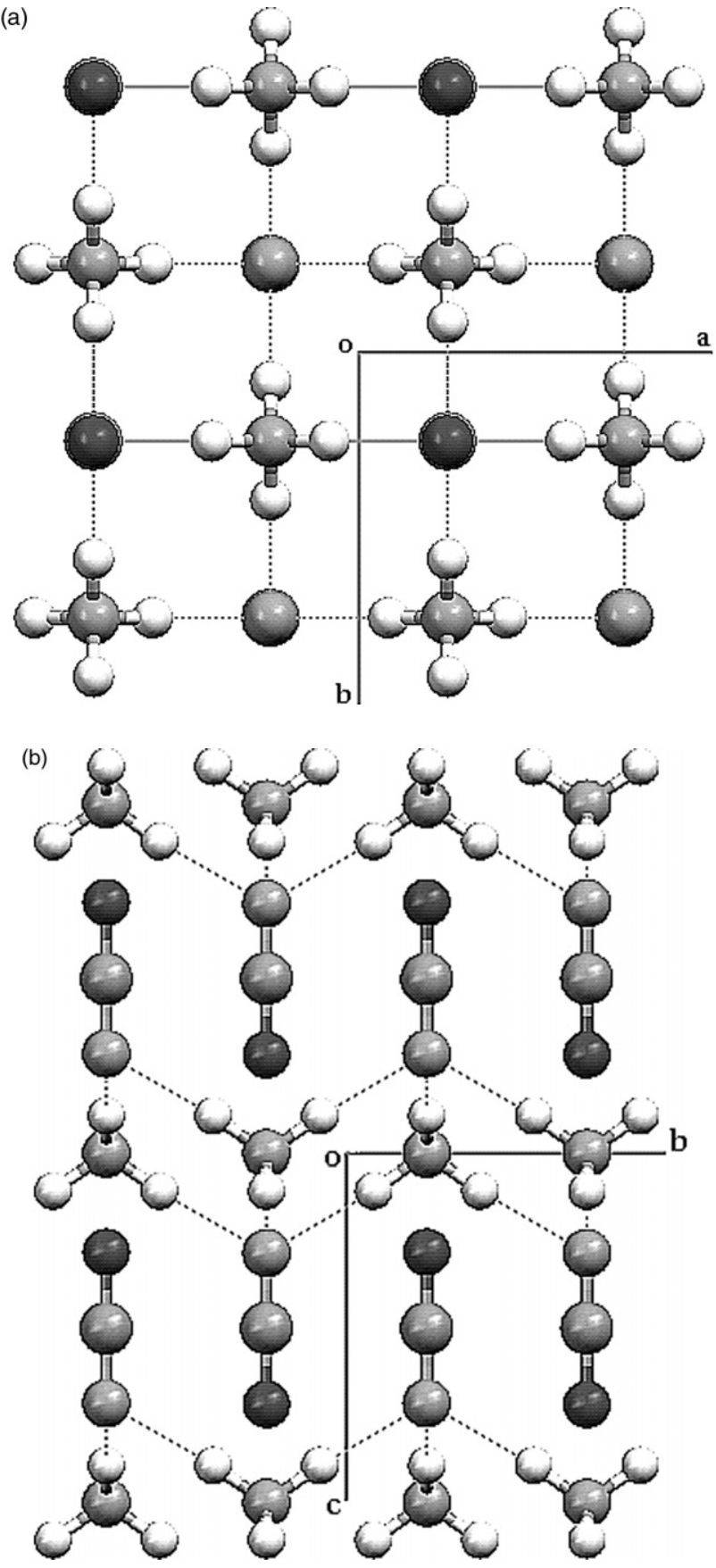

Figure 1. Crystal structure of ammonium cyanate determined by powder neutron diffraction at $14 \mathrm{~K}$. (a) View along the $c$ axis. (b) View along the $a$ axis. In both figures, the oxygen atoms in the cyanate anion are dark grey, nitrogen atoms are light grey and hydrogen bonds are shown as dotted lines.

from Structure II in the gas phase towards Structure I in solid ammonium cyanate.

The cation site symmetry and the arrangement of the nearest atoms in ammonium cyanate are similar to those in the ammonium scheelites [9]. Initially, it was thought that if the energy difference between the two orientations of the ammonium cation were not too large, pseudo-spin effects may affect the thermal expansion and other physical properties of ammonium cyanate, in the same manner as in ammonium perrhenate and ammonium metaperiodate. However, the neutron diffraction results for ammonium cyanate [4] covering a wide temperature range below room temperature indicate that the thermal expansion of ammonium cyanate is normal in both directions. It may be deduced that the higher energy orientation of the cation is not significantly populated at room temperature, as indeed confirmed from the neutron diffraction studies.

With this background, a study of the structure of solid ammonium cyanate has been carried out using density functional methods. The density functional approach has been used previously to study the structure and dynamics of several ammonium salts [10-13], and was successful in predicting the structures of $\mathrm{NH}_{4} \mathrm{Cl}$ and $\mathrm{NH}_{4} \mathrm{~F}$, and vibrational spectra of the latter salt. In addition, it was shown that at the transition state for rotation about an $\mathrm{N}-\mathrm{H}$ bond, the ammonium ion is subjected to distortion and displacement as it rotates $[11,12]$. The breaking of three hydrogen bonds allows the fourth to pull the whole cation off its normal position in the crystal, with $\mathrm{N}-\mathrm{H}$ bond extension and partial transfer of a proton from the (acidic) ammonium ion to the (basic) anion. If a similar process occurs in crystalline ammonium cyanate, then it may be involved in the initiation of the solid state reaction in which the salt is converted to urea.

Recently, Tsipis and Karipidis [14] studied the mechanism of the Wöhler reaction using ab initio calculations, and concluded that, both in vacuum and in the crystal, the first step of the reaction in vacuum is the transfer of a proton from the ammonium ion to the cyanate ion to form isocyanic acid HNCO, as suggested previously $[3,4]$. This step is followed by addition of an ammonia molecule to the $\mathrm{N}=\mathrm{C}$ double bond. It is plausible that the proton transfer step in the reaction in the crystal may be facilitated by rotation of the ammonium ion about an $\mathrm{N}-\mathrm{H}$ bond.

In the present study, two parallel but independent calculations have been carried out to study the structure and dynamics of the ammonium cyanate crystal. The methods used and the results for the two calculations, referred to as methods I and II, are presented separately, and then compared.

\section{Methodology}

\subsection{Computational method I}

The first computational method used is similar to that described previously $[10,11]$, namely the FEMD 
(a)

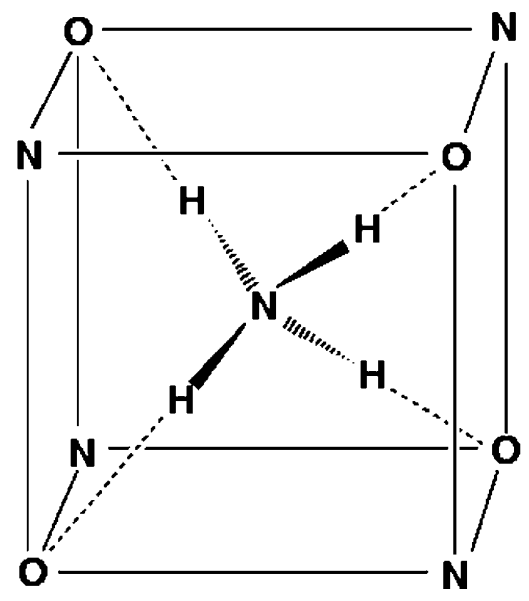

(b)

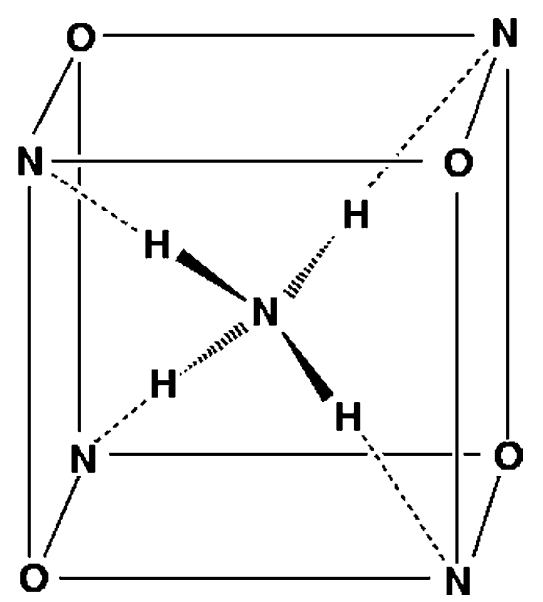

Figure 2. Schematic illustrations of the distorted cube in the crystal structure of ammonium cyanate, with $\mathrm{O}$ and $\mathrm{N}$ atoms of cyanate anions at alternate corners. Two different orientations of the ammonium cations are shown, corresponding to (a) the formation of $\mathrm{N}-\mathrm{H} \cdots \mathrm{O}$ hydrogen bonds and $(b) \mathrm{N}-\mathrm{H} \cdots \mathrm{N}$ hydrogen bonds.

method of Alavi et al. [15]. In this method, a free energy functional is optimized, yielding at self-consistency the electronic free energy. The method uses a density functional with the local density approximation and BLYP gradient corrections [16, 17]. Troullier-Martins pseudo-potentials [18] in the Kleinman-Bylander form [19] using s-non-locality for the $\mathrm{C}, \mathrm{N}$ and $\mathrm{O}$ atoms were used. We used a Monkhorst-Pack grid of $2 \times 2 \times 2$ $k$-point mesh to sample the Brillouin zone for the primitive unit cell; trial calculations using a $4 \times 4 \times 4$ mesh gave a negligible difference to the results.

The structure was optimized within the tetragonal unit cell with the dimensions determined by powder X-ray diffraction [3], namely $a=b=5.143 \AA, \mathrm{c}=5.555 \AA$, giving $c / a=1.080$. The initial coordinates for the hydrogen atoms were based upon an $\mathrm{N}-\mathrm{H}$ bond length of $1.025 \AA[10]$ and the hydrogen atoms on the mirror planes of the $P 4 / \mathrm{nmm}$ space group so as to give either the $\mathrm{N}-\mathrm{H} \cdots \mathrm{O}$ or $\mathrm{N}-\mathrm{H} \cdots \mathrm{N}$ orientation of the ammonium ion. The unit cell dimensions were then varied to minimize the energy of the crystal with the ammonium ion in the lower energy $\mathrm{N}-\mathrm{H} \cdots \mathrm{N}$ orientation, with the internal structure optimized at every step. The minimum energy was achieved with a slightly different value of $a(5.283 \AA)$ and the same ratio $c / a=1.080$, but the lowering of the energy was not significant and the original unit cell dimensions from the powder X-ray diffraction study were used in subsequent work.

The force constants were determined by displacing each atom from its optimized position by a small distance along the unit cell axes. The force constants were computed from the first derivatives of the forces on the atoms, and the vibrational wavenumbers and eigenvectors were computed from the appropriate dynamical matrices.

In the transition state for cation rotation about an $\mathrm{N}-\mathrm{H}$ bond, the cation is symmetrically situated with respect to one of the mirror planes, and so the geometry of the transition state could be optimized within this constraint, as was done for ammonium fluoride and chloride [11]. Only one of the two cations in the unit cell was placed in the transition state, while the other remained in the most stable orientation.

\subsection{Computational method II}

In the second set of calculations, the density functional program SIESTA [20] was used. The calculations were performed using the Kleinman-Bylander form [19] of Troulliers-Martins pseudo-potentials [18]. Exchange-correlation effects were treated with the BLYP functional [16, 17]. All calculations used a splitvalence DZP basis set and a $2 \times 2 \times 2$ MonkhorstPack grid of $k$ points.

The geometry of the structure was optimized using the conjugate gradients method. The starting geometry for the calculations was taken as the structure obtained in the powder neutron diffraction study [4], with unit cell parameters $a=b=5.082 \AA, c=5.551 \AA$. In space group $P 4 / n m m$, the $\mathrm{N}-\mathrm{H} \cdots \mathrm{N}$ and $\mathrm{N}-\mathrm{H} \cdots \mathrm{O}$ forms of the structure correspond to the hydrogen atoms lying on the mirror planes. The two structures are related by $90^{\circ}$ rotation of the ammonium cation about the $\overline{4}$ axis parallel to $c$. In all calculations, the unit cell parameters were simultaneously optimized together with the atomic coordinates. However, constraints were applied to the stress components on the unit cell such that tetragonal metric symmetry was maintained. 
In order to study the energy barrier and structural changes associated with the rotation of the ammonium ion, a number of rotated structures were generated by moving the position of the unique hydrogen atom of the ammonium ion, corresponding to rotation about the crystallographic $\overline{4}$ axis. The geometries of these structures, including the unit cell parameters, were subsequently optimized using the method described above. During each geometry optimization calculation, the angle through which the ammonium ion was rotated was maintained by applying appropriate constraints upon the forces on the hydrogen atoms, although the bond lengths and bond angles within the ammonium ion were allowed to vary. Obviously, in those structures for which the hydrogen atom does not lie on the mirror planes of the $P 4 / n m m$ space group, the symmetry is lowered to $P 4 / n$. However, tetragonal metric symmetry was again maintained by appropriate constraints upon the unit cell parameters. Finally, we note that our calculations represent the situation in which all ammonium ions in the crystal structure simultaneously participate in an equivalent rotation.

\section{Results}

\subsection{The equilibrium structure}

The first approach, method I, was applied to analyse the equilibrium structure of ammonium cyanate. For both orientations of the ammonium ion, the optimization converged to a stable atomic configuration, with the $\mathrm{N}-\mathrm{H} \cdots \mathrm{N}$ orientation, shown in figure 1, having the lower energy. In both orientations, the $\mathrm{H}$ atoms in the optimized structure are located on the mirror planes. The optimized structures for both the $\mathrm{N}-\mathrm{H} \cdots \mathrm{N}$ and $\mathrm{N}-\mathrm{H}$. . O orientations are given in table 1. The energy of the crystal in the $\mathrm{N}-\mathrm{H}$... O orientation is higher by $24.4 \mathrm{~kJ}$ per mole of formula unit $\mathrm{NH}_{4} \mathrm{NCO}$. Thus, the calculations confirm the results of the neutron diffraction analysis [4]: the space group is $P 4 / n m m$ and the $\mathrm{N}-\mathrm{H} \cdot \mathrm{N}$ orientation of the ammonium cation is of lower energy than the $\mathrm{N}-\mathrm{H}$... O orientation.

The energy difference of $24.4 \mathrm{~kJ} \mathrm{~mol}^{-1}$ between the two orientations is appreciably larger than the apparent energy difference of $1100 \mathrm{~K}$, or $9.1 \mathrm{~kJ} \mathrm{~mol}^{-1}$, between the two corresponding orientations in ammonium perrhenate [21], and so it is unlikely that pseudo-spin effects, in the thermal expansion for example, would show up in ammonium cyanate at room temperature. This is consistent with the neutron diffraction results, which show a normal thermal expansion below room temperature [4].

The calculated bond lengths within the cyanate ion are significantly different in the two orientations of the cation (table 1 ). In the more stable $\mathrm{N}-\mathrm{H} \cdots \mathrm{N}$ orientation, the bond lengths are $r(\mathrm{~N}-\mathrm{C})=1.203 \AA$ and $r(\mathrm{C}-\mathrm{O})=1.207 \AA$, which agree well with the neutron diffraction results at $14 \mathrm{~K}(r(\mathrm{~N}-\mathrm{C})=1.191(5) \AA$ and $r(\mathrm{C}-\mathrm{O})=1.215(5) \AA)$ [4]. Bond lengths in silver cyanate $\mathrm{AgNCO}$ determined by $\mathrm{X}$-ray diffraction are $r(\mathrm{~N}-\mathrm{C})=1.195(11) \AA$ and $r(\mathrm{C}-\mathrm{O})=1.180(11) \AA[22]$. The near equality of the $\mathrm{N}-\mathrm{C}$ and $\mathrm{C}-\mathrm{O}$ bond lengths in these crystals is in contrast to the difference between the bond lengths in the gas phase cyanate ion. The interionic hydrogen bond length is $r(\mathrm{H} \cdots \mathrm{N})=1.932 \AA$.

In the $\mathrm{N}-\mathrm{H}$. . O orientation, the bond lengths in the cyanate anion are $r(\mathrm{~N}-\mathrm{C})=1.181 \AA$ and $r(\mathrm{C}-\mathrm{O})=$ $1.249 \AA$, suggesting that if the cation adopted this orientation, the anion would be best described as $\mathrm{N} \equiv \mathrm{C}-\mathrm{O}^{-}$. The interionic hydrogen bond length is $r(\mathrm{H} \cdots \mathrm{O})=1.934 \AA$.

The equilibrium structure of ammonium cyanate has also been analysed using method II. The geometry optimization calculations proceeded in a straightforward manner, and no convergence problems were encountered. The results indicate that the $\mathrm{N}-\mathrm{H} \cdots \mathrm{N}$ form of the structure is lower in energy by $26.03 \mathrm{~kJ}$ per mole of formula unit $\mathrm{NH}_{4} \mathrm{NCO}$, thus corroborating the results of the powder neutron diffraction study [4] and the FEMD calculations detailed above.

Although there are slight differences due to the different computational methodologies, the optimized

Table 1. Calculated equilibrium crystal structure of ammonium cyanate for two orientations of the ammonium cation. Tetragonal $P 4 / n m m, Z=2$, origin at $2 / \mathrm{m}$. Cation $\mathrm{N}$ is at $1 / 4,3 / 4,0$. Anion atoms are at $1 / 4,1 / 4, z$. Energy is in $\mathrm{kJ} \mathrm{mol}^{-1}$ relative to the more stable $\mathrm{N}-\mathrm{H} \cdots \mathrm{N}$ orientation of the cation. Bond distances are in $\AA$, and bond angles are in degrees.

\begin{tabular}{|c|c|c|c|c|}
\hline & \multicolumn{2}{|c|}{ Method I } & \multicolumn{2}{|c|}{ Method II } \\
\hline \multicolumn{5}{|c|}{ Cation orientation } \\
\hline & $\mathrm{N}-\mathrm{H} \cdots \mathrm{N}$ & $\mathrm{N}-\mathrm{H} \cdot \cdots \mathrm{O}$ & $\mathrm{N}-\mathrm{H} \cdots \mathrm{N}$ & $\mathrm{N}-\mathrm{H} \cdots \mathrm{O}$ \\
\hline$a$ & 5.143 & 5.143 & 5.260 & 5.246 \\
\hline$c$ & 5.555 & 5.555 & 5.551 & 5.554 \\
\hline \multicolumn{5}{|c|}{ Energy } \\
\hline$E$ & 0.0 & 24.4 & 0.0 & 26.0 \\
\hline \multicolumn{5}{|c|}{ Fractional coordinates } \\
\hline$x_{H}$ & 0.416 & $1 / 4$ & 0.416 & $1 / 4$ \\
\hline$y_{H}$ & $3 / 4$ & 0.914 & $3 / 4$ & 0.914 \\
\hline$z_{H}$ & 0.107 & 0.107 & 0.109 & 0.109 \\
\hline$z_{N}$ & 0.733 & 0.702 & 0.743 & 0.706 \\
\hline$z_{C}$ & 0.516 & 0.489 & 0.526 & 0.493 \\
\hline$z_{O}$ & 0.299 & 0.264 & 0.308 & 0.266 \\
\hline \multicolumn{5}{|c|}{ Bond lengths } \\
\hline $\mathrm{N}-\mathrm{H}$ & 1.042 & 1.034 & 1.059 & 1.050 \\
\hline $\mathrm{N}-\mathrm{C}$ & 1.203 & 1.181 & 1.207 & 1.179 \\
\hline $\mathrm{C}-\mathrm{O}$ & 1.207 & 1.249 & 1.212 & 1.261 \\
\hline \multicolumn{5}{|c|}{ Bond angle $H-N-H$ (bisected by c-axis) } \\
\hline & 110.3 & 109.7 & 110.6 & 109.7 \\
\hline
\end{tabular}


geometries determined by computational methods I and II are in close agreement. In the optimized $\mathrm{N}-\mathrm{H} \cdots \mathrm{N}$ structure, we find unit cell parameters $a=b=5.260 \AA$, $c=5.551 \AA$, corresponding to an increase of approximately $7 \%$ in the unit cell volume after optimization. For the $\mathrm{N}-\mathrm{H} \cdots \mathrm{N}$ structure, the bond lengths in the cyanate anion are found to be $r(\mathrm{~N}-\mathrm{C})=1.207 \AA$ and $r(\mathrm{C}-\mathrm{O})=1.212 \AA$, in good agreement with the neutron diffraction results at $14 \mathrm{~K}$. The ammonium ion bond length was found to be $r(\mathrm{~N}-\mathrm{H})=1.059 \AA$, and the interionic hydrogen bond length is $r(\mathrm{H} \cdots \mathrm{N})=1.939 \AA$.

For the $\mathrm{N}-\mathrm{H} \cdots \mathrm{O}$ structure, the optimized unit cell parameters were found to be $a=b=5.246 \AA, c=$ $5.554 \AA$. As expected purely on the basis of the geometries, the differences in the unit cell parameters between the $\mathrm{N}-\mathrm{H} \cdots \mathrm{N}$ and $\mathrm{N}-\mathrm{H} \cdots \mathrm{O}$ forms are small. The cyanate anion bond lengths were found to be $r(\mathrm{~N}-\mathrm{C})=1.179 \AA$ and $r(\mathrm{C}-\mathrm{O})=1.261 \AA$. Again, these results and those of the FEMD calculations detailed above are in close agreement. The bond length in the ammonium cation was found to be $r(\mathrm{~N}-\mathrm{H})=1.050 \AA$, and is very similar to that found for the $\mathrm{N}-\mathrm{H} \cdots \mathrm{N}$ form. The interionic hydrogen bond length was found to be $r(\mathrm{H} \cdots \mathrm{O})=1.966 \AA$.

\subsection{Rotation of the ammonium cation}

\subsubsection{Rotation about an $\mathrm{N}-\mathrm{H}$ bond}

The transition state for rotation of the ammonium cation about an $\mathrm{N}-\mathrm{H}$ bond was studied using method I. This transition state is reached when the ammonium ion rotates by $60^{\circ}$ about an $\mathrm{N}-\mathrm{H}$ bond. In this configuration, two of the hydrogen atoms are located on a mirror plane, and the other two are symmetrically placed on opposite sides of this plane, so the forces perpendicular to the mirror plane are zero. In the calculations, an ion placed in this configuration remains at the transition state while the atomic positions in the unit cell are optimized [11]. If one of the two cations in each unit cell is rotated to this configuration, then over the whole crystal alternate ions are at the transition state. Clearly, this situation does not represent the rotation of a single isolated cation, but should nevertheless be indicative of the geometry and energy of the transition state.

In the resulting transition state geometry, the rotated cation is pulled off its equilibrium site in the direction of the $\mathrm{N}-\mathrm{H}$ rotation axis by $0.21 \AA$, and the $\mathrm{N}-\mathrm{H}$ bond about which rotation occurs is stretched slightly by $0.020 \AA$, to $1.062 \AA$. The other three $\mathrm{N}-\mathrm{H}$ bonds of the rotated cation shorten slightly. There are no large changes in the bond angles. The geometry of the cation in the transition state is very similar to that predicted in ammonium fluoride, for the case in which alternate cations are rotated [11]. One of the anions is slightly tilted away from the $c$ axis as the cation rotates. The energy of the transition state is higher than that of the equilibrium structure by $34.8 \mathrm{~kJ}$ per mole of unit cells, comprising two formula units of $\mathrm{NH}_{4} \mathrm{NCO}$ (note that, in this case, we consider the energy per mole of unit cells as this corresponds to the energy per mole of rotated ammonium cations, allowing direct comparison with the results presented in section 3.2.2).

A vibrational analysis was carried out for the transition state with a displacement of $0.2 \mathrm{au}$. The calculation indicated one imaginary frequency of $295 \mathrm{~cm}^{-1}$ corresponding to a torsional mode, confirming that this is indeed a true transition state.

It is intriguing to speculate that the displacement and distortion of ammonium ions at the transition state for rotation about $\mathrm{N}-\mathrm{H}$ bonds may assist in the transfer of a proton from the (acidic) ammonium cation to the (basic) cyanate anion. This has been suggested as the first step of the reaction in which urea is formed [3, 4, 14]. Note that the geometry of approach of the proton in the crystal is about right for formation of the bent $\mathrm{H}-\mathrm{N}-\mathrm{C}$ bond in the isocyanic acid molecule.

\subsubsection{Rotation about the $\overline{4}$ axis}

The geometry of the ammonium cyanate crystal structure was optimized for a range of rotation angles of the ammonium ion about the $\overline{4}$ axis. These calculations used method II, described in section 2.2. In these calculations, a rotation angle of $0^{\circ}$ corresponds to the $\mathrm{N}-\mathrm{H} \cdots \mathrm{N}$ form and a rotation angle of $90^{\circ}$ corresponds to the $\mathrm{N}-\mathrm{H} \cdots \mathrm{O}$ form. The variation in energy of the structure with rotation angle, relative to the lower energy $\mathrm{N}-\mathrm{H} \cdots \mathrm{N}$ form, is shown in figure 3 .

The barrier to rotation about the $\overline{4}$ axis is found to be $42.6 \mathrm{~kJ}$ per mole of formula units $\mathrm{NH}_{4} \mathrm{NCO}$ (which corresponds, in this case, to the energy per mole of rotated ammonium cations). The maximum in energy corresponds to a rotation angle of about $50^{\circ}$. This is higher than the minimum barrier for rotation about an $\mathrm{N}-\mathrm{H}$ bond calculated above. This result may be seen to be directly related to the increased number of hydrogen bonds which must be broken during the rotation about the $\overline{4}$ axis (all four hydrogen bonds broken) compared to the rotation about an $\mathrm{N}-\mathrm{H}$ bond (three hydrogen bonds broken; the other hydrogen bond strengthened). Our results therefore support the suggestion above that the rotation about the $\mathrm{N}-\mathrm{H}$ bond is the preferred rotational mode. However, it is relevant to note that in our calculations, the transition state for rotation about the $\mathrm{N}-\mathrm{H}$ bond corresponds to a situation in which half the ammonium cations in the unit cell are rotated and half are unrotated, whereas the transition state for rotation about the $\overline{4}$ axis corresponds to a situation in which all ammonium cations in the unit cell 


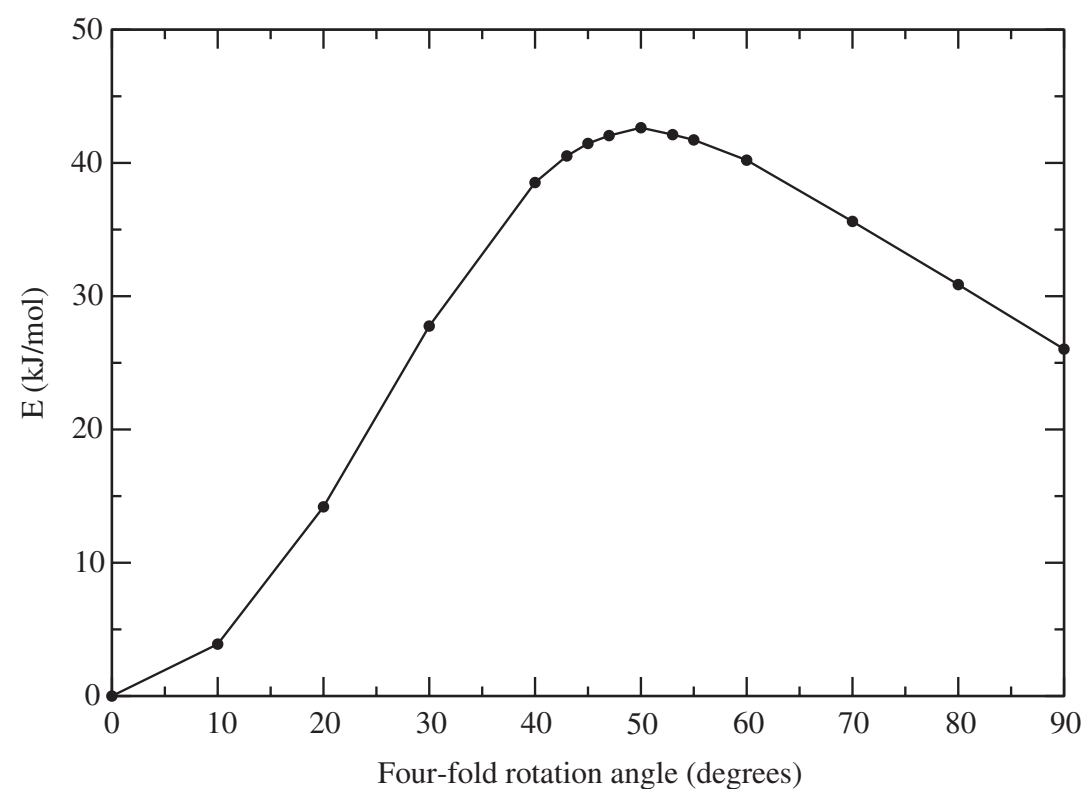

Figure 3. Variation in the energy per $\mathrm{NH}_{4} \mathrm{NCO}$ unit as the ammonium cations are rotated around the $\overline{4}$ axes, calculated by computation method II. A rotation angle of $0^{\circ}$ corresponds to the $\mathrm{N}-\mathrm{H} \cdots \mathrm{N}$ structure and a rotation angle of $90^{\circ}$ corresponds to the $\mathrm{N}-\mathrm{H} \ldots \mathrm{O}$ structure. The maximum barrier height is found to be $42.6 \mathrm{~kJ} \mathrm{~mol}^{-1}$ at a rotation angle of $50^{\circ}$.

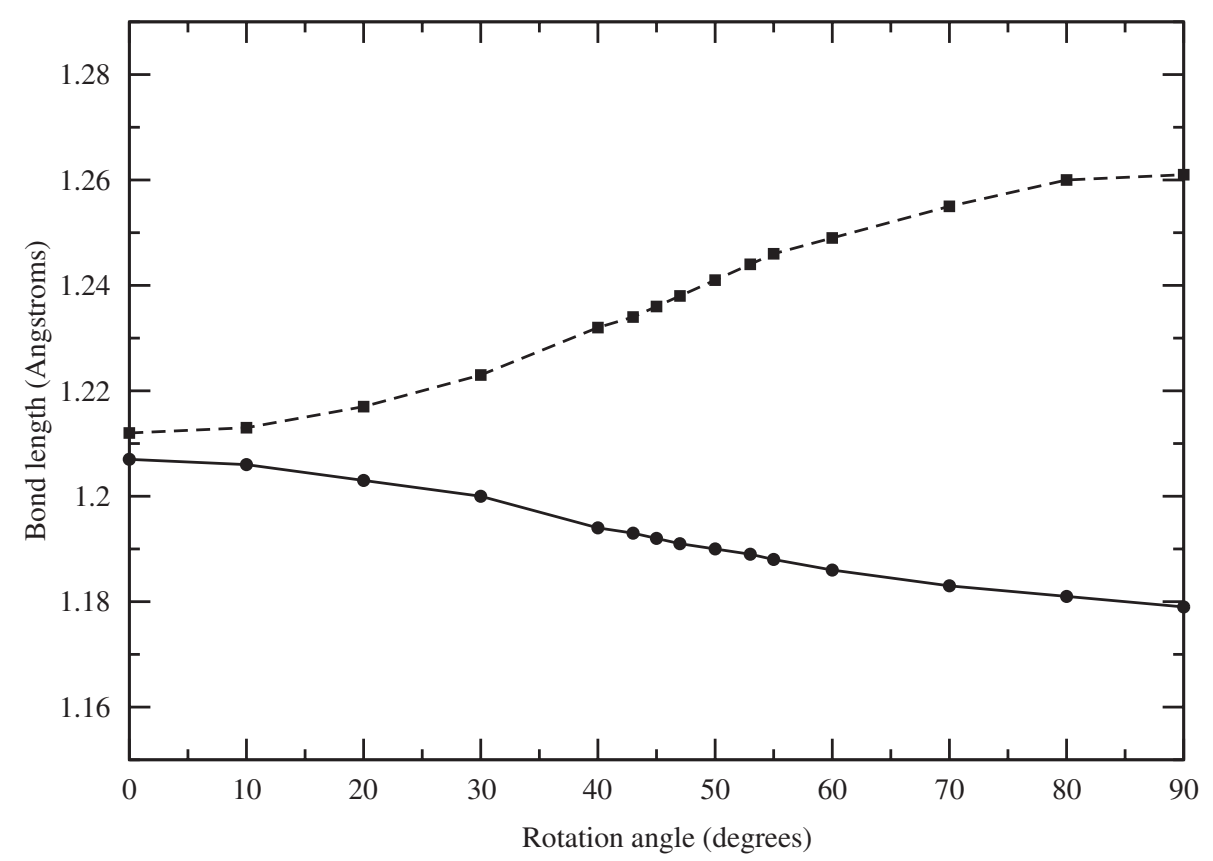

Figure 4. Variation of bond lengths in the cyanate anion as the ammonium cations are rotated around the $\overline{4}$ axes, calculated by computation method II. The solid line represents the variation in the $\mathrm{N}-\mathrm{C}$ bond length and the dashed line represents the variation in the $\mathrm{C}-\mathrm{O}$ bond length. The curves indicate a smooth change in the contributions of the two possible valence descriptions of the anion, ${ }^{-} \mathrm{N}=\mathrm{C}=\mathrm{O}$ and $\mathrm{N} \equiv \mathrm{C}-\mathrm{O}^{-}$.

are rotated. Future studies will explore the extent to which correlation between rotations of different ammonium cations influence the rotation barrier, although such effects are unlikely to alter the conclusion, deduced from the present study, that the barrier is lower for rotation about the $\mathrm{N}-\mathrm{H}$ bond.

From figure 4, it may be seen that the variation in the bond lengths of the cyanate anion during the 
$90^{\circ}$ rotation is smooth and monotonic, even as the energy passes through the maximum. The changes in the $\mathrm{N}-\mathrm{H}$ bond lengths during rotation are negligible, with a maximum variation of $0.016 \AA$. In terms of the crystal structure, it is therefore difficult to propose a point at which the cyanate anion 'switches' between the two possible valence bond descriptions. The electronic structure of the cyanate anion is apparently very sensitive to the external influence of the hydrogen bonds from the ammonium cation.

\subsection{Vibrational spectrum}

The vibrational spectrum of ammonium cyanate was studied using the computational approach described in section 2.1. The wavenumbers for the vibrational spectrum were computed from forces calculated for two different atomic displacements, 0.01 and $0.1 \mathrm{au}$, from the equilibrium positions for the $\mathrm{N}-\mathrm{H} \cdots \mathrm{N}$ structure. The results for both displacements are listed in table 2; the vibrational symmetries were determined by examination of the eigenvectors. The results for the smaller displacement of $0.01 \mathrm{au}$ are closer to the true harmonic frequencies than those for the larger displacement, but for the low frequency modes the calculated forces are too small to yield reliable frequencies. Hence, for the lower frequency modes, only the larger displacement results are reliable. This is consistent with the results of previous calculations of the vibrational spectrum of ammonium fluoride [13]. For the high frequency modes, the results for the smaller displacement may be more accurate because of anharmonicity.

There appear to be no published experimental data on the vibrational properties of ammonium cyanate for comparison, but it is nevertheless clear that the computed internal mode frequencies for the cation are in the right frequency ranges. The computed anion stretching frequencies are somewhat lower than tabulated values for the isocyanate group $\mathrm{N}=\mathrm{C}=\mathrm{O}$ in organic molecules, which are about 2270 and $1420 \mathrm{~cm}^{-1}$ [23]. In the gas phase anion, the experimental vibrational frequencies are 2148 and $1233 \mathrm{~cm}^{-1}$ (stretching), and $625 \mathrm{~cm}^{-1}$ (bending) [5]. For spectra of the cyanate anion in solution, it is common to refer to the higher frequency as a $\mathrm{CN}$-stretch and the lower frequency as a CO-stretch [24], but examination of the eigenvectors shows that, at least in the crystal, these vibrations are better described as symmetric and asymmetric stretching modes of the whole ion.

The librational frequencies of the ammonium cation are similar to the calculated frequencies in ammonium fluoride [13]. The very low frequency degenerate modes consist of a mixture of translational motion and librational motion of the anions. Some of the low frequency modes involve the entire hydrogen bonded
Table 2. Wavenumbers for vibrational modes of ammonium cyanate.

\begin{tabular}{|c|c|c|c|c|}
\hline \multirow{2}{*}{\multicolumn{2}{|c|}{$\begin{array}{l}\text { Orientation: } \\
\text { Atomic displacement: }\end{array}$}} & \multirow{2}{*}{\multicolumn{3}{|c|}{$\begin{array}{ccc}\mathrm{N}-\mathrm{H} \cdots \mathrm{N} & \mathrm{N}-\mathrm{H} \cdots \mathrm{N} & \mathrm{N}-\mathrm{H} \cdots \mathrm{C} \\
0.01 \mathrm{au} & 0.1 \mathrm{au} & 0.1 \mathrm{au}\end{array}$}} \\
\hline & & & & \\
\hline Mode & Symmetry & $v / \mathrm{cm}^{-1}$ & $v / \mathrm{cm}^{-1}$ & $v / \mathrm{cm}^{-1}$ \\
\hline \multirow{12}{*}{$\begin{array}{l}\text { anion libration } \\
\text { anion libration } \\
\text { chain } \\
\text { anion trans. } \\
\text { cation trans. } \\
\text { chain } \\
\text { chain } \\
\text { trans. } \\
\text { cation libration }\end{array}$} & $\mathrm{E}_{\mathrm{g}}$ & & 100.6 & 104.0 \\
\hline & $\mathrm{E}_{\mathrm{u}}$ & & 125.9 & 139.6 \\
\hline & $\mathrm{E}_{\mathrm{g}}$ & & 133.3 & 136.5 \\
\hline & $A_{1 g}$ & & 138.5 & 142.7 \\
\hline & $A_{1 g}$ & & 160.7 & 145.3 \\
\hline & $\mathrm{E}_{\mathrm{u}}$ & & 223.0 & 211.3 \\
\hline & $\mathrm{E}_{\mathrm{g}}$ & & 237.0 & 234.0 \\
\hline & $\mathrm{A}_{2 \mathrm{u}}$ & & 237.2 & 230.8 \\
\hline & $\mathrm{E}_{\mathrm{g}}$ & 477.1 & 447.4 & 344.9 \\
\hline & $\mathrm{E}_{\mathrm{u}}$ & 507.2 & 477.7 & 381.0 \\
\hline & $\mathrm{A}_{2 \mathrm{~g}}$ & 500.3 & 500.4 & 388.4 \\
\hline & $\mathrm{B}_{1 \mathrm{u}}$ & 586.7 & 587.2 & 501.5 \\
\hline \multirow[t]{2}{*}{ anion bend } & $\mathrm{E}_{\mathrm{u}}$ & 585.5 & 626.6 & 594.3 \\
\hline & $\mathrm{E}_{\mathrm{g}}$ & 595.3 & 635.7 & 600.2 \\
\hline \multirow[t]{2}{*}{ anion symm. str. } & $A_{1 g}$ & 1287.0 & 1281.2 & 1192.9 \\
\hline & $\mathrm{A}_{1 \mathrm{u}}$ & 1288.9 & 1282.5 & 1195.5 \\
\hline \multirow[t]{4}{*}{ cation bend } & $\mathrm{B}_{1 \mathrm{~g}}$ & 1433.7 & 1422.1 & 1410.5 \\
\hline & $\mathrm{E}_{\mathrm{u}}$ & 1400.4 & 1472.2 & 1453.8 \\
\hline & $\mathrm{A}_{2 \mathrm{u}}$ & 1448.1 & 1481.3 & 1473.2 \\
\hline & $E_{g}$ & 1488.0 & 1491.3 & 1472.8 \\
\hline \multirow[t]{4}{*}{ cation scissors } & $\mathrm{B}_{2 \mathrm{u}}$ & 1689.0 & 1675.9 & 1677.2 \\
\hline & $\mathrm{A}_{1 \mathrm{u}}$ & 1677.7 & 1676.3 & 1659.4 \\
\hline & $A_{1 g}$ & 1766.7 & 1717.4 & 1710.1 \\
\hline & $\mathrm{B}_{2 \mathrm{~g}}$ & 1730.0 & 1764.9 & 1755.9 \\
\hline \multirow[t]{2}{*}{ anion asym. str. } & $A_{1 g}$ & 2097.5 & 2130.4 & 2166.2 \\
\hline & $\mathrm{A}_{2 \mathrm{u}}$ & 2136.3 & 2167.2 & 2191.5 \\
\hline \multirow[t]{2}{*}{ cation sym. str. } & $\mathrm{B}_{2 \mathrm{u}}$ & 3057.3 & 3063.8 & 3196.8 \\
\hline & $A_{1 g}$ & 3098.4 & 3105.4 & 3230.2 \\
\hline \multirow[t]{4}{*}{ cation asym. str. } & $\mathrm{B}_{1 \mathrm{~g}}$ & 3059.4 & 3068.7 & 3240.6 \\
\hline & $\mathrm{E}_{\mathrm{g}}$ & 3073.7 & 3083.5 & 3246.4 \\
\hline & $\mathrm{E}_{\mathrm{u}}$ & 3056.7 & 3084.4 & 3247.2 \\
\hline & $\mathrm{A}_{2 \mathrm{u}}$ & 3136.4 & 3158.6 & 3307.3 \\
\hline
\end{tabular}

network (involving the $\mathrm{N}$ end of the anions) and have been labelled as chain modes. The $\mathrm{O}$ ends of the anions are not involved in hydrogen bonding and undergo large amplitude librational oscillations in several modes.

The vibrational spectrum was also calculated for the structure with all ammonium cations in the $\mathrm{N}-\mathrm{H} \cdots \mathrm{O}$ orientation. Although this configuration of the crystal is not observed experimentally, it is important to note that real, rather than imaginary, frequencies are predicted for all the expected modes. This indicates that, with this orientation of the cation, the energy of the crystal would be at a stable minimum and not a saddle point. The $\mathrm{N}-\mathrm{H}$... O hydrogen bond seems to be weaker than the $\mathrm{N}-\mathrm{H} \cdots \mathrm{N}$ hydrogen bond, as judged from the calculated $\mathrm{N}-\mathrm{H}$ bond length and cation stretching frequencies. 


\section{Acknowledgements}

RJCB wishes to express his appreciation of more than a decade of productive collaboration with Professor Ruth Lynden-Bell during a sabbatical year and subsequent visits to Cambridge and Belfast, and thanks her for hospitality and many stimulating discussions. She has made valuable contributions during discussions of the present study.

This work was supported by the Natural Sciences and Engineering Research Council of Canada. RJCB gratefully acknowledges financial support from Trinity College, Cambridge.

KDMH, RLJ and SH gratefully acknowledge financial support from the University of Birmingham and EPSRC, and discussions with Professor J. D. Dunitz, FRS, and Professor Julian Gale are also gratefully acknowledged.

\section{References}

[1] Wöhler, F., 1828, Poggendorffs Ann., 12, 253.

[2] Cohen, P. S., and Cohen, S. M., 1996, J. Chem. Ed., 79, 883.

[3] Dunitz, J. D., Harris, K. D. M., Johnston, R. L., Kariuki, B. M., Maclean, E. J., Psallidas, K., SchweIzer, W. B., and Tykwinski, R. R., 1998, J. Am. chem. Soc., 120, 13274.

[4] Maclean, E. J., Harris, K. D. M., Kariuki, B. M., Kitchin, S. J., Tykwinski, R. R., Swainson I. P., and Dunitz, J. D., 2003, J. Am. chem. Soc., 125, 14449.

[5] Bradforth, S. E., Kim, E. H., Arnold, E. W., and Neumark, D. M., 1993, J. chem. Phys., 98, 800.

[6] CAI, Z.-L., 1993, Chem. Phys., 170, 33.
[7] Schultz, P. W., Leroi, G. E., and Harrison, J. F., 1996, Molec. Phys., 88, 217.

[8] Cheung, Y.-S., and Li, W.-K., 1997, Aust. J. Chem., 50, 169.

[9] Swainson, I. P., and Brown, R. J. C., 1997, Acta Crystallogr., B53, 76.

[10] Alavi, A., Lynden-Bell, R. M., and Brown, R. J. C., 1998, Can. J. Chem., 76, 1581.

[11] Alavi, A., Lynden-Bell, R. M., and Brown, R. J. C., 1999, J. Chem. Phys., 110, 5861.

[12] Alavi, A., Lynden-Bell, R. M., and Brown, R. J. C., 2000, Chem. Phys. Lett., 320, 487.

[13] Alavi, A., Lynden-Bell, R. M., and Brown, R. J. C., 2001, J. Raman Spectrosc., 32, 996.

[14] Tsipis, C. A., and Karipidis, 2003, J. Am. chem. Soc., $125,2307$.

[15] Alavi, A., Kohanoff, J., Parinello, M., and Frenkel, D., 1994, Phys. Rev. Lett., 73, 2599.

[16] Becke, A. D., 1988, Phys. Rev. A, 38, 3098.

[17] Lee, C., Yang, W., and Parr, R. G., 1988, Phys. Rev. B, 37,785 .

[18] Troullier, N., and Martins, J. L., 1991, Phys. Rev. B, 43, 1993.

[19] Kleinman, L., and Bylander, D. M., 1982, Phys. Rev. Lett., 48, 1425.

[20] Soler, J. M., Artacho, E., Gale, J. D., Garcia, A., Junquera, J., Ordejón, P., and SÁnchez-Portal, D., 2002, J. Phys.: condens. Matter, 14, 2745.

[21] Taylor, D. R., 1989, Phys. Rev. B, 40, 493.

[22] Britton, D., and Dunitz, J. D., 1965, Acta Crystallogr., 18, 424.

[23] Lambert, J. B., Shurvell, H. F., Lightner, D. A., and Cooks, R. G., 1998, Organic Structural Spectroscopy (Engelwood Cliffs, NJ: Prentice Hall).

[24] Schultz, P. W., Leroi, G. E., and Popov, A. I., 1995, J. Am. chem. Soc., 117, 10735. 